\title{
Os bibliotecários baianos: compreendendo a evolução de uma profissão
}

\author{
The Bahian Librarians: understanding the evolution of a profession
}

\begin{abstract}
Jaires Oliveira Santos Doutoranda em Ciência da Informação pelo Programa de Pós-graduação em Ciência da Informação da Universidade Federal da Bahia - UFBA. E-mail: jairesoliveira@gmail.com

Maria Isabel de Jesus Sousa Barreira Doutora em Educação pela Universidade Federal da Bahia - UFBA. Professora adjunta da Universidade Federal da Bahia - UFBA.

E-mail: isasousa2010@ hotmail.com
\end{abstract}

\begin{abstract}
Resumo
O estudo buscou compreender o espaço de memória ocupado pelos bibliotecários formados na Universidade Federal da Bahia entre os anos de 1980 a 2012. Nessa perspectiva, lançou-se um olhar sobre alguns aspectos relacionados à formação e atuação profissional do bibliotecário, a fim de compreendê-lo enquanto sujeito da memória individual e coletiva responsável pela mediação do conhecimento humano produzido socialmente. Utilizou-se como instrumentos de coleta de dados fontes primárias que integram a memória institucional, tais como livros de atas de colação de grau, assim como três livros comemorativos, referentes aos 40, 50 e 60 anos da antiga Escola de Biblioteconomia e acervos fotográficos relativos à trajetória da Instituição. A pesquisa caracteriza-se como exploratória documental, pretendeu percorrer as trilhas da memória institucional, onde transitaram pessoas, anseios, sonhos, crises, e, um desejo comum de adquirir uma formação profissional para exercer uma carreira.
\end{abstract}

Palavras-chave: Bibliotecários. Memória Institucional. Espaço educativo. Biblioteconomia Baiana.

\begin{abstract}
The study sought to understand the memory space occupied by Librarians trained at the Federal University of Bahia, between the years of 1980 to 2012. In this perspective, has a look at some aspects of the formation and professional performance, in order to understand it while na agent of individual and collective memory which is responsible for the mediation of human knowledge produced socially. Used as data collection instruments primary sources that are part of the institutional memory, such as books of minutes of graduation, as well as three commemorative books, concerning 40, 50 and 60 years of the old School of Library, and, photographic collections relating to the history of the institution. The research is characterized as exploratory-documentary, intended to traverse the trails of institutional memory, where have passed: people, aspirations, dreams, crises, and a common desire to acquire professional training to get a career.
\end{abstract}

Keywords: Librarians. Institutional Memory. Educational space. Bahian Librarianship. 


\section{Introdução}

A Biblioteconomia enquanto profissão é uma conquista do mundo contemporâneo, entretanto há registros das atividades inerentes à práxis biblioteconômica desde a idade antiga, mencionando as atividades de Calímaco, reconhecido como primeiro bibliotecário da história. Nessa trajetória, que vai da Biblioteca de Alexandria, passando pelas bibliotecas das ordens religiosas da Idade Média até os dias atuais, a ação desses profissionais garante a organização, o tratamento, a preservação e a disseminação do conhecimento socialmente produzido pelo homem.

A competência secular para organizar, tratar e disseminar a informação evoluiu com a própria história do conhecimento, com a explosão informacional do século $\mathrm{XX}$ e a democratização do acesso à informação. Vale ressaltar que a demanda informacional fez com que a profissão e o profissional se adequassem a cada inovação surgida no seio da sociedade, sendo o seu perfil constantemente transformado para atender os anseios dos usuários da informação. As atividades inerentes ao profissional bibliotecário ganharam reconhecimento a partir do século XVII, quando o livro ultrapassou o limite do uso restrito para ganhar uma nova configuração e importância social na formação do conhecimento.

Na perspectiva de compreender o espaço de memória ocupado pela Biblioteconomia, a pesquisa buscou identificar e analisar o percurso formativo do bibliotecário graduado na Escola de Biblioteconomia e Documentação, atual Instituto de Ciência da Informação, da Universidade Federal da Bahia (ICI/UFBA) ao longo dos seus 70 anos de história. Em razão da exiguidade de tempo, realizou-se um recorte temporal, a fim de possibilitar a execução do estudo. Desse modo, o período escolhido se estendeu entre os anos de 1980 a 2012, pautado no conjunto das informações oriundas de documentos existentes no ICI, bem como aquelas prestadas pelo Conselho Regional de Biblioteconomia (CRB 5). Os dados foram obtidos por meio de questionários aplicados junto aos bibliotecários.

A investigação revisitou a própria identidade profissional baiana, tanto individual como institucional. Para tanto, buscou-se na literatura subsídios que tratam do processo de formação do profissional bibliotecário bem como aqueles que tangenciam a memória individual e coletiva, atreladas à memória institucional. Utilizou-se como ferramental de trabalho os recursos informacionais de fontes primárias que integram a memória institucional, tais como livros de atas de colação de grau, onde estão registrados os nomes de todos os formandos no período investigado. 
Tal pesquisa, com base em um estudo exploratório documental, não pretendeu ser definitiva, mas sim sugerir a relevância prática de percorrer as trilhas da memória institucional, onde transitaram pessoas, anseios, sonhos, crises e um desejo comum de adquirir uma formação profissional para exercer uma carreira.

De todo o mosaico de elementos integrantes da memória institucional no contexto analisado (documentos, imagens, livros comemorativos e eventos), o profissional bibliotecário é o ator social - um agente da memória - responsável pela organização, tratamento e disseminação da informação e as bibliotecas espaços privilegiado de memória social.

\section{A profissão de bibliotecário: contexto histórico}

A Biblioteconomia, segundo Tozzi e Burgo (2012), tem sua origem nos primórdios da humanidade, onde há relatos de que as bibliotecas reuniam, inicialmente, milhares de tábuas de argila; mais tarde aparecem as coleções de papiros e pergaminhos, que registram o saber humano à época. Esses espaços de guarda da memória social seguem os passos da evolução da escrita e as diversas formas de registro do conhecimento humano.

A Biblioteca de Alexandria, no Egito, a mais famosa da antiguidade, criada no século III a.C., constituiu-se no grande marco da história das bibliotecas da Antiguidade, chegando a reunir cerca de 700 mil volumes de manuscritos. Compreendia dez grandes salas e ambientes separados para os consulentes. Nesse espaço de memória, coube ao bibliotecário Calímaco, de Cirene, a tarefa organizar o conhecimento ali disposto, por meio de técnicas biblioteconômicas (ordenação por assunto e por ordem alfabética) para torná-lo acessível e de fácil manuseio.

Na Idade Média, a evolução social ampliou-se e diversificou esses espaços de guarda de conhecimento, surgindo as bibliotecas dos mosteiros e de ordens religiosas diversas, as bibliotecas das universidades e as bibliotecas particulares, quase sempre pertencentes a reis, nobres ou grandes senhores (MARTINS, 2002). Estas últimas constituem a origem das bibliotecas nacionais e representavam símbolos de poder e acúmulo de conhecimento para os poucos que tinham o privilégio de acessá-las e consultar seus acervos.

Desde o surgimento das bibliotecas até o período da Renascença, os guardiões da memória eram sacerdotes ou figuras das classes dominantes. Não gozavam de um status social como bibliotecários, tal como hoje configurado; viviam confinados em mosteiros e trabalhavam em suas bibliotecas, preocupados em salvaguardar o acervo e realizar a 
reprodução - cópia das obras. Neste período, eram denominados copistas por reproduzirem as obras, dando origem ao termo cópia, hoje amplamente usado. Martins, ao contextualizar a profissão do bibliotecário, apresenta duas fases distintas: uma que vai “(...) da Renascença até meados do século XIX”, período em que o bibliotecário é um profissional contratado por instituições particulares, sem formação especializada, quase sempre um erudito ou um escritor a quem se oferecia oportunidade de realizar em paz a sua obra, livre de preocupações materiais (MARTINS, 2002, p. 235)

A outra fase inicia na segunda metade do século XIX e, que segundo Martins (2002, p. 235):

[...] o estado reconhece o bibliotecário como representante de uma profissão socialmente indispensável. Nesta segunda fase, o sistema de confiar as grandes bibliotecas a escritores e eruditos, sem formação técnica ainda continua por algum tempo, logo aparecerá, por força da própria especialização, a necessidade de fazer do bibliotecário um funcionário especificamente treinado para as suas funções.

A evolução propiciada pelo avanço científico e tecnológico do século XX possibilita a diversificação dos suportes informacionais e, com isso, a ampliação dos acervos que agora contam com multimeios, filmes, CDs, DVDs, fotografias, além dos tradicionais periódicos, revistas, jornais e livros.

A explosão informacional promovida pelas tecnologias de comunicação e informação fez com que surgisse a Ciência da Informação, área que tem como matriz a Biblioteconomia e cuja preocupação reside no tratamento das questões relacionadas à informação e suas peculiaridades (LE COADIC, 2004). Nesse contexto de múltiplas possibilidades, as instituições responsáveis pela formação do bibliotecário vão paulatinamente ampliando suas competências para se adequar a essas mudanças e melhor qualificar o profissional para atender as demandas advindas do mercado de trabalho.

\subsection{A profissão no Brasil}

A institucionalização da Biblioteconomia no Brasil remonta à vinda da família real portuguesa em 1808, trazendo, entre outras coisas, o acervo original pertencente à Biblioteca da Corte Portuguesa, o qual posteriormente se integra à Biblioteca Nacional. A biblioteca da Corte era constituída pela Livraria Real (biblioteca privativa dos monarcas) e a do Infantado (biblioteca destinada aos infantes, filhos dos soberanos portugueses). Vê-se, portanto, que no primeiro momento a coleção era restrita aos membros da corte portuguesa, para em seguida ser aberta ao público em 1814. 
A instalação de biblioteca no Brasil demandou a criação de um curso para capacitar os profissionais que ali iriam atuar. Assim, com um lapso temporal de mais de 100 anos desde a chegada da Família Real, nascia o primeiro curso para formação do profissional bibliotecário no país. Este foi concebido em 1911, mas só teve início efetivamente em 1915, na Biblioteca Nacional do Rio de Janeiro, funcionando até 1923, e objetivava formar profissionais com perfil de cultura geral - que contemplasse as diversas áreas do conhecimento, evidenciando a influência, da cultura erudita europeia.

O crescimento da Biblioteconomia ocorreu de forma gradativa e relacionado ao contexto educacional do país. Em 1936, surge o primeiro curso de Biblioteconomia de São Paulo. Em 1940, houve a expansão do ensino e as oportunidades de ingressar na carreira se ampliaram para outros estados, como Bahia, Pernambuco, Minas Gerais e, São Paulo (Campinas), entre outros. Sobre esse processo evolutivo no Brasil, Job e Oliveira (2006) dizem que : "de 1911 até os anos 40 foram criados quarenta e dois cursos, dos quais alguns desapareceram, outros surgiram nos anos posteriores, abrangendo 20 Estados e o Distrito Federal”.

Esse cenário cria condições para que a classe una forças e propicie o surgimento de instituições voltadas à defesa dos profissionais bibliotecários, a exemplo da Federação Brasileira de Associações de Bibliotecários, Cientistas da Informação e Instituições (FEBAB), em 1959 (FEBAB, 2012).

Em seguida, uma conquista importante que vai definitivamente sedimentar a profissão no Brasil foi o seu reconhecimento legal, em 30 de junho de 1962, com a promulgação da Lei 4.098, complementada pela Lei 9.674, de 25 de junho de 1998, que regulamenta o exercício da profissão. Dentre outras exigências está a do registro profissional no Conselho Regional de Biblioteconomia.

\subsection{A profissão na Bahia}

Um curso de extensão em Biblioteconomia da Biblioteca Nacional, no Rio de Janeiro, foi o que impulsionou a Engenheira Bernadete Sinay Neves, responsável pela Biblioteca da Escola Politécnica da Bahia, a criar o curso de Biblioteconomia. Neves tinha uma enorme disposição no sentido de difundir novas maneiras de cuidar dos livros. 
Em 1942, ministrou o primeiro curso na área de Biblioteconomia, na Escola da Politécnica, onde trabalhava. Em seguida, foi a São Paulo fazer um curso de Especialização. Ao retornar, em 1944, ofereceu o segundo curso de Biblioteconomia, no Instituto Geográfico e Histórico. Na sequência, foi estudar nos Estados Unidos, para aprimorar seus conhecimentos na área. De volta a Salvador, em 1946, ministrou o terceiro curso de Biblioteconomia. Ao retornar ao seu estado de origem, Bernadete funda a Escola de Biblioteconomia, que posteriormente foi integrada à Universidade da Bahia (CASTRO, 2006).

Em 1947, a Escola de Biblioteconomia da Bahia começou a funcionar nas dependências da Escola Politécnica da Universidade da Bahia; posteriormente, foi alocada nas dependências da Faculdade de Filosofia, Escola de Belas Artes, Escola de Ciências Econômicas, subsolo da Reitoria, na rua Araújo Pinho. Atualmente, o curso superior de Biblioteconomia é sediado no Instituto da Ciência da Informação (ICI), no bairro Canela, antigo prédio da casa da Espanha. Barreto e Barreira (2009, p. 51) asseveram com propriedade o impacto social que teve a inserção do curso de Biblioteconomia na Bahia, na universidade, o que agregou visibilidade e novas perspectivas profissionais para a área:

A inserção da Escola de Biblioteconomia da Bahia na universidade por força de um
convênio, em 1954, trouxe novas perspectivas para a área e seus profissionais, dando-
lhes maior visibilidade na sociedade baiana. A escola passou a denominar-se (sic)
Escola de Biblioteconomia e Documentação da Universidade da Bahia.

A visibilidade da Biblioteconomia na sociedade baiana hoje está muito atrelada não só ao curso superior, mas também àqueles que o representam como atores sociais, que fazem do curso a realidade do seu cotidiano, sendo potenciais mediadores entre os acervos e o público usuário. Pode-se afirmar que o processo de destacar a Biblioteconomia baiana é do tipo colaborativo e coletivo, na medida em que cada bibliotecário desempenha o seu papel como um ator social mediador do conhecimento, da informação e da cultura. É nessa perspectiva que a Escola de Biblioteconomia da Bahia se constitui como um lócus de memória individual e coletiva de uma profissão, onde sujeitos sociais foram educados para desempenhar uma profissão. 


\section{Memória institucional: aspectos individuais e coletivos}

Etimologicamente, a palavra memória vem do latim memor e oris que significa "o que lembra". No âmbito individual, a memória tem sido considerada como uma capacidade não só de reter informações atuais, como de armazenar e conservar certas informações ao longo do tempo. Le Goff (1996, p. 423), ao abordar a memória individual, ressalta que é por meio dela que "o homem pode atualizar impressões ou informações passadas, ou que ele representa como passadas". Schacter (1999) define a memória como "um telescópio apontado ao tempo". Inserida neste contexto está o conceito de memória individual, que se entrelaça- com o conceito de memória coletiva. Conforme Halbwachs (2006, p. 69): ratifica "diríamos que cada memória individual é um ponto de vista sobre a memória coletiva, que este ponto de vista muda segundo o lugar que ali ocupo e que esse mesmo lugar muda segundo as relações que mantenho com outros ambientes".

Para Peter Burke (2000), a memória tem uma função de fonte histórica, com a qual o historiador analisa a confiabilidade do que é relembrado via cruzamento com outras fontes e com a fluência da história oral. Então surge o fenômeno histórico, ou seja, uma "história social do lembrar". Burke (2000) extrapola o conceito de memória oral e particular e menciona as funções de uma memória social; faz correlações interessantes como a contraposição entre memória social e amnésia estrutural (onde o esquecimento tem a finalidade de imposição, interesses políticos e antidemocráticos); ele também apresenta a relação entre lugar e memória (no âmbito da construção da identidade nacional), ou o que ele define como "comunidades de memória".

Finalmente, Burke (2000, p. 84) alerta para a falta de preservação adequada, o que leva à destruição de documentos, da memória e, por consequência, do conhecimento histórico. As memórias social e coletiva podem ser definidas no entrelaçar das memórias individuais com outros indivíduos, com lugares e com oportunidades, no tempo e no espaço. Nesse contexto, surge a necessidade do bibliotecário ter uma noção dessa acepção dupla da memória social - a memória individual e a memória coletiva - além de desenvolver uma boa cultura geral e noções de História, notadamente do país e da região onde atua.

No âmbito da memória social onde a universidade está inserida, emerge ainda o conceito de memória institucional que cabe ser explorado aqui. A memória institucional foi definida por Costa (1997, p. 153) como 
[...] um elemento primordial no funcionamento das instituições. É através da memória que as instituições se reproduzem no seio da sociedade, retendo apenas as informações que interessam ao seu funcionamento. [...] um processo seletivo que se desenvolve segundo regras instituídas e que variam de instituição para instituição. E as informações relevantes para a recuperação da memória institucional devem ser, por isso, buscadas não apenas nos materiais e fontes internas, mas fora dos muros institucionais. A memória institucional está em permanente elaboração, pois é função do tempo.

É nesse contexto que esse estudo centra seu foco para compreender o bibliotecário enquanto sujeito de memória, partícipe de um processo de formação profissional. Nos seus estudos, Costa (1997) afirma que são os próprios indivíduos os agentes e ativos construtores que fazem a memória da instituição, no espaço e no tempo presente. Essa construção memorial é espelhada nos registros dessa trajetória social e histórica, nos registros e lembranças que se tem no presente de eventos, dos acertos e desacertos, das diferentes ideologias, das crises e conflitos que são lembrados pela memória individual e coletiva, em construção no tempo presente, como corroborado nesta frase da pesquisadora: "precisamos construir uma memória institucional no tempo presente, o único de que dispomos, já que o passado já passou, e o futuro está em nossas mãos.” (COSTA, 1997, p. 155).

O conceito de memória institucional apresentado por Costa (1997) se relaciona com a proposta do presente estudo no escolher como fontes primárias de pesquisa os dados pessoais de bibliotecários graduados que estão listados nos livros e atas pertencentes à Escola de Biblioteconomia, atual ICI/UFBA, ao logo dos 70 anos de fundação da instituição, com um recorte temporal no período de 1980 a 2012.

No processo de construção da memória institucional pode impactar a peculiaridade individual do ato de lembrar, no tempo e no espaço, bem como o conceito individual de memória, o modo como cada pessoa valoriza suas memórias correlacionando-as com o resgate de sua identidade, enquanto ser humano que busca sua formação acadêmica na área de Biblioteconomia. O resgate das memórias pessoais e coletivas é descrito por Fentress e Wickham (1992) como o processo que inclui o acúmulo de conhecimento que mostra como somos, configurando assim nossa própria identidade. Desta forma, um estudo da maneira como nos lembramos - a maneira como nos apresentamos nas nossas memórias, a maneira como definimos as nossas identidades pessoais e coletivas por meio das nossas memórias, a maneira como ordenamos e estruturamos as nossas ideias nas nossas memórias e a maneira como transmitimos essas memórias a outros - é o estudo da maneira como somos (FENTRESS; WICKHAM, 1992). 
Estudos sobre memória, como o do neurocientista Damásio et al. (2010), apontam que a memória está relacionada com a emoção. Segundo o autor, sem emoção não se consolida o processo de memória. Nesse sentido, é possível compreender que, na constituição da memória institucional, relembrar as datas comemorativas de cunho institucional é um modo prático que impacta na memória coletiva. Aqui podemos citar a celebrações anuais em relação ao ano de fundação das bibliotecas, bem como a data de fundação do curso de Biblioteconomia como eventos oportunos para experienciar o conceito emergente de memória institucional.

Infere-se que celebrar as datas comemorativas institucionais também no ciberespaço é importante tanto para a instituição como para o bibliotecário, pois estará tocando no lado emocional, tanto do público usuário - memória coletiva - como na memória individual de alunos e professores. Revisitar as datas comemorativas institucionais tenderá a resultar num fenômeno memorial, não só em relação à data e ao acontecimento rememorado, mas também servindo como subsídio para outras pesquisas.

Não é objetivo desse estudo esgotar a temática da memória institucional, mas mencionála como relevante e fundamental no processo tanto informacional como educacional dos profissionais. Tal cenário é explicitado por Costa (1996, p. 71): “a memória institucional parece invadir as fronteiras do quadro temporal, para suscitar questões do vivido. O que ontem era ocultado, silenciado, segregado, pode hoje apresentar-se como realidade a ser (re)vista no campo institucional.)."

No campo institucional, sugere-se oportuno incluir na formação acadêmica a construção, individual e coletiva, do conceito emergente de memória institucional. Tal inclusão colaborará para o desenvolvimento da consciência do ator social bibliotecário, na medida em que os profissionais tenham a consciência de que são os representantes da instituição frente à sociedade. Essa representatividade se dá pela via de um trabalho ético e exemplar, e colabora para a difusão e a construção da memória institucional para além das fronteiras dos prédios da Universidade, configurando-se em um bem intelectual, cultural e profissional intangível, compartilhado com a sociedade.

No processo de construção das memórias, individual e coletiva, bem como do processo de construção da memória institucional, impactam tanto a emoção como o modo como as ideias e lembranças são estruturadas e processadas nessa construção, que é um ato contínuo, no tempo e no espaço, inserido no contexto institucional. 


\section{Apresentação dos dados e discussão dos resultados}

As informações coletadas nessa pesquisa foram, a priori, tabuladas, tratadas quanti/qualitativamente e, a partir daí, chegou-se a um mapeamento do perfil do profissional egresso no curso de Biblioteconomia UFBA.

A categoria perfil profissional abarca as questões relacionadas ao gênero, ano de conclusão do curso, tempo de atuação na área, a motivação para a escolha do curso e a preocupação com a educação continuada, buscando compreender a correlação que se estabelece na formação da identidade-memória de cada profissional egresso no período estudado. A análise dos dados evidencia que o gênero predominante continua sendo feminino (80\%). Esse resultado reafirma os obtidos nos estudos de Martucci (1996), ainda que se observe a crescente inserção de homens na área.

Para situar o sujeito no espaço institucional de formação profissional, buscou-se identificar o período de conclusão do curso de graduação. Os dados evidenciaram que $43 \%$ dos egressos participantes desta pesquisa finalizaram a sua graduação após os anos 2000, os demais em anos que antecederam essa data.

Os dados revelaram que $60 \%$ da amostra está no mercado de trabalho há mais de 11 anos, demonstrando uma experiência considerável no exercício profissional dos bibliotecários investigados.

As escolhas profissionais quase sempre provocam indecisões e por vezes são influenciadas por sujeitos que fazem parte do contexto social vivenciado. Desse modo, a motivação para a escolha do curso de Biblioteconomia foi uma questão levantada no estudo, a fim de compreender as influências que determinaram a trajetória profissional. Relembrar as circunstâncias que determinaram a escolha profissional consiste em um modo de estabelecer relações entre si e outros indivíduos para a construção da memória individual e coletiva. A pesquisa evidenciou que a maioria dos egressos (57\%) escolheu a profissão por determinação própria. Curiosamente, a influência do professor não foi considerada pelos participantes, o que leva a crer que os professores do ensino médio pouco conhecem esse profissional e, portanto, não influenciam nem incentivam os alunos. Nesse sentido, talvez sejam necessárias ações mais contundentes por parte do curso de Biblioteconomia nas escolas, a fim de tornar esta área conhecida no âmbito das instituições educacionais. Destaca-se nessa trajetória, de acordo com os dados, que a influência de amigos foi relevante para a escolha profissional, levando a crer

InCID: R. Ci. Inf. e Doc., Ribeirão Preto, v. 8, n. 1, p. 68-80, mar./ago. 2017. 
que a memória individual é influenciada pelas inter-relações estabelecidas com outros sujeitos sociais.

A pesquisa buscou também identificar a realidade dos participantes no que se refere à sua preocupação com a educação continuada (Especialização, Mestrado, Doutorado e outra Graduação). Os dados demonstraram que os profissionais investigados se preocupam com a capacitação profissional, uma vez que $71 \%$ cursaram Especialização, buscando aprimorar seus conhecimentos. Nesse sentido, Prosdócimo e Ohira (2000) ressaltam que "a Educação continuada prepara o indivíduo para executar melhor aquilo que já realiza, focalizar o como fazer, capacitando-o para atuar na realidade atual como também, para o futuro". Por outro lado, Valentim (2002) enfatiza que a responsabilidade de se capacitar após a saída da escola é papel do próprio profissional. Há de se ressaltar que desse total existe ainda aqueles que cursaram mestrado e doutorado (16\% e 3\% respectivamente), reforçando a crença de que os egressos do curso de Biblioteconomia no período analisado procuram efetivamente se qualificar para atender às exigências do mercado de trabalho.

Cabe salientar que neste processo é relevante que os cursos de Biblioteconomia ofereçam regularmente cursos de extensão e especialização, além daqueles voltados à pósgraduação stricto sensu - mestrado e doutorado -, a fim de oportunizar aos egressos ampliarem sua formação por meio da Educação continuada (CUNHA, 1984).

\section{Considerações finais}

A memória institucional, muito além de um mero conceito emergente correlacionado à memória coletiva de Halbwachs (2006), é um processo de construção, individual e coletivo, além de colaborativo, que rompe os limites dos muros de uma instituição. Esse dinamismo inerente à memória institucional está relacionado diretamente com a temática da presente investigação, ajudando a compor um panorama, em constante evolução, da Biblioteconomia baiana e um perfil de seus atores sociais, os profissionais bibliotecários.

A relação identidade-memória pode ser vislumbrada na trajetória individual da formação de cada profissional que passou pela instituição. O modo como as ideias são estruturadas na memória individual e o modo como ela é transmitida aos outros impacta no processo de construção da memória institucional, construindo-se num ato contínuo. Pelo estudo 
realizado, infere-se que a identidade-memória ocupa um tempo e um espaço, inclui a própria instituição educacional, seu corpo docente e discente, os funcionários e colaboradores.

Vale mencionar a perenidade institucional, na qual as pessoas vêm e vão, chegam a desaparecer da instituição, mostrando o seu lado transitório; entretanto, a instituição eternizase na proporção da continuidade dos serviços relevantes de ensino superior que ela presta à comunidade.

O presente estudo não pretende esgotar a temática ora apresentada, nem tampouco que os resultados da análise dos dados sejam conclusivos, pois eles representam olhar sobre o universo amostral pesquisado de bibliotecários, formados entre o período de 1980-2012.

Numa perspectiva geral do trabalho, pretende-se ampliar a reflexão sobre o perfil do profissional formado pela Escola de Biblioteconomia e Documentação (ICI) da UFBA no sentido de incentivar a elaboração de novas pesquisas sobre a temática ora investigada.

\section{Referências}

BARRETO, A. M.; BARREIRA, M. I. J. S. Fragmentos de uma preciosa memória: Esmeralda Aragão e a Biblioteconomia na Bahia. Salvador: EDUFBA, 2009.

BURKE, P. Variedades de história cultural. Rio de Janeiro: Civilização Brasileira, 2000.

CASTRO, C. A. História da Biblioteconomia brasileira: perspectiva histórica. Brasília: Thesaurus, 2006.

COSTA, I. T. M. Memória institucional: a construção conceitual numa abordagem teóricometodológica. 1997. 169 f. Tese (Doutorado em Ciência da Informação) - Universidade Federal do Rio de Janeiro, Rio de Janeiro. 1997.

Informare. Cadernos do programa de pós-graduação em Ciência da Informação, Rio de Janeiro, v. 2, n. 2, p. 67-72, jul./dez, 1996.

CUNHA, M. B. O desenvolvimento profissional e a educação continuada. Revista de Biblioteconomia de Brasília, Brasília, v. 12, n. 2, p. 145-156, jul./dez. 1984.

DAMÁSIO, A. et al. Especial: a conquista da memória. Revista Veja, São Paulo, ed. 2147, jan. 2010. Disponível em: <http://veja.abril.com.br/130110/conquista- memoria-p078.shtml>. Acesso: 28 jul. 2013.

FEBAB. Missão e histórico. 2012. Disponível em: 〈http://febab.org.br/?page_id=39>. Acesso em: 28 jul. 2013.

FENTRESS, J.; WICKHAM, C. Memória social. Lisboa: Teorema, 1992. 
HALBWACHS, M. A memória coletiva. São Paulo: Centauro, 2006.

LE GOFF, J. História e memória. Campinas: UNICAMP, 1996.

MARTINS, W. A palavra escrita. São Paulo: Ática, 2002.

MARTUCCI, E. M. A feminilização do magistério e da Biblioteconomia: uma aproximação. Perspectivas em Ciência da Informação, Belo Horizonte, v. 1, n. 2, p. 225-244, jul./dez. 1996.

PROSDÓCIMO, Z. P. A.; OHIRA, M. L. B. Quem é o bibliotecário em exercício no Estado de Santa Catarina: necessidade de educação continuada. In: CONGRESSO BRASILEIRO DE BIBLIOTECONOMIA E DOCUMENTAÇÃO, 19., 2000, Porto Alegre. Anais... Porto Alegre, 2000. [CD-ROM].

SCHACTER, D. L. En busca de la memoria. Barcelona: Grupo Zeta, 1999.

TOZZI, F. C.; BURGO, P. C. F. Biblioteca, conhecimento e cultura condicionantes de projeto no centro cultural de palmital, 2012. Disponível em:

<http://fio.edu.br/cic/anais/2012_xi_cic/PDF/Arq/11.pdf>. Acesso em: 28 jul. 2013.

VALENTIM, M. L. P. (Org.). Formação do profissional da informação. São Paulo: Polis, 2002. 